\title{
A Clinical Study Assessing the Surrounding Bone Levels and Bone Density of Implant-borne and Implant-tooth-fixed Partial Dentures
}

\author{
Mohamed T Hamed ${ }^{1}$, Hisham A Mously ${ }^{2}$
}

\begin{abstract}
Background: Advanced developments in the field of dentistry have observed the utilization of implants as a manageable treatment approach for edentulous patients. In addition, the rapid emergence of cone-beam computed tomography (CBCT) is aforethought significant, particularly for optimum implant installation. The objective of this investigation is to radiographically evaluate the bone density and alveolar bone height in the vicinity of implants and premolars in tooth-implant sustained fixed partial dentures (FPDs) with rigid connector vs implant-implant supported FPDs with rigid connector using CBCT.

Materials and methods: The height and width of the implant were taken into consideration. A sample of eight patients was used having both males and females, aged between 30 years and 45 years with good oral hygiene and divided into two groups. Patients within group I were given a tooth-implant-supported FPD associated to the dental implant at the site of mandibular second molar. On the contrary, patients of group II were given an implant-implant FPD associated to a distal implant at the site of second molar. For evaluating the bone quality of each patient, preoperative panoramic radiographs using the orthopantomograph OT 100 and CBCT images using Scanora 3D were constructed. Results: The findings of the current study indicated that there was no statistically substantial discrepancy among values of bone density in groups. Conclusion: It is concluded that progressive loading tends to increase the bone density by time.

Keywords: Alveolar bone height, Bone density, Tooth-implant-supported fixed partial denture.

World Journal of Dentistry (2019): 10.5005/jp-journals-10015-1669
\end{abstract}

\section{INTRODUCTION}

Recent developments in the dental field have witnessed the use of implants as a viable treatment approach for partially or completely edentulous patients, having a significant success rate of over $90 \%$. There has been burgeoning interest in the usage of fixed partial dentures (FPDs) supported by implants for prosthetic restorations of such patients. ${ }^{2}$ Aforesaid FPDs typically incorporate the use of titanium as the implant material due to its favorable properties of inertness under high temperatures and tolerance of physiological solutions for an infinite period of time without corrosion. ${ }^{3}$

Hoffmann and Zafiropoulos ${ }^{4}$ discussed that the amalgamated incorporation of teeth and implants for prosthetic restoration may be disadvantageous to the functionality of the dentition. Such implants cannot allow a degree of physical mobility at the same level of a normal tooth. However, the maximal displacement that can be afforded by implants is $10 \mathrm{~m}$. $^{5}$ This difference between the level of support afforded by the natural tooth and the osseointegrated implant means that there is a behavioral difference in response to the masticatory forces. ${ }^{4}$ Such differences have resulted in intense load being placed on the prosthetic restoration, osseointegrated implant, and abutments. It may also result in mechanical fracture, tooth intrusion, and a greater risk of development of caries at the crown margin. ${ }^{6}$ In order to reduce the adverse effects, it has been recommended to use rigid connectors of variable designs. ${ }^{6}$

Complex reconstruction cases of implants impart the use of computed tomography (CT) and cone-beam computed tomography (CBCT). ${ }^{7}$ While CT has unfavorable associated effects such as elevated levels of radiation exposure, big expenditure, massive imprint, and inconvenience, CBCT generates lower dose of radiation as the image intensifier rotates once to produce the required image. ${ }^{7}$
${ }^{1}$ Department of Oral and Maxillofacial Prosthodontics, Faculty of Dentistry, King Abdulaziz University, Kingdom of Saudi Arabia; Department of Fixed Prosthodontics, Faculty of Dentistry, Cairo University, Egypt

${ }^{2}$ Department of Oral and Maxilofacial Prosthodontics, Faculty of Dentistry, King Abdulaziz University, Kingdom of Saudi Arabia

Corresponding Author: Hisham A Mously, Department of Oral and Maxilofacial Prosthodontics, Faculty of Dentistry, King Abdulaziz University, Kingdom of Saudi Arabia, Phone: +966 55738 8777, e-mail: dr.mously@gmail.com

How to cite this article: Hamed MT, Mously HA. A Clinical Study Assessing the Surrounding Bone Levels and Bone Density of Implantborne and Implant-tooth-fixed Partial Dentures. World J Dent 2019;10(5):379-383.

Source of support: Nil

Conflict of interest: None

It is to be noted that there is an abundance of literature pertaining to implant-supported prostheses; however, very few studies targeted the effects of utilizing a tooth-implant FPD in relation to bone structure of dentition. ${ }^{4}$ The objective of this investigation is to radiographically assess the alveolar bone density and height in the vicinity of implants and premolars in tooth-implant supported FPDs with rigid connector against implant-implant supported FPDs with rigid connector using $\mathrm{CBCT}$. Therefore, this study further aims to contribute to the limited literature pertaining to such tooth-implant FPDs and ascertain their efficacy and effectiveness in partially edentulous patients. 


\section{Materials and Methods}

\section{Participants}

Eight partially edentulous patients (six males and two females), aged between 30 years and 45 years, were picked from the outpatient clinic of Dental Department, Research Institute of Ophthalmology. The general health of the patient was evaluated through real oral, clinical, and physical examinations that were carried out to ensure acceptable conditions. These subjects were free from any systematic or incapacitating disease that would alter the quality or healing of bone. Only patients with good oral hygiene were selected. Their residual ridges were of suitable width and height for implant placement and covered by firm mucoperiostum. Additionally, their opposing arch was either dentulous or partially edentulous resorted by a fixed restoration. Furthermore, these patients had a normal maxilla-mandible relationship (Angle's class I ridge classification) with adequate interarch space and accepted occlusion. A healthy periodontal condition of the abutment tooth was selected to evaluate the effects of prosthesis on sound health periodontium, and the patients were motivated to maintain oral hygiene to avoid periodontal disease that may lead to bone resorption.

Patients with gagging reflexes, temporomandibular joint disorder, bruxism, clenching habits, heavy smokers and those who had already received radiotherapy to the head and neck regions were excluded from this study. A local consultation of all patients was done for any concerns and ethical issues of research, where a consent was taken from all patients before the study. Full medical history of the patients was recorded, including previous and recent illnesses, surgeries, and complications.

\section{Research Process}

The patients were asked regarding the reason behind their tooth loss, date of their last tooth extraction, and pain or clicking in the temporomandibular joint. Mouth preparation was carried out prior the investigation. Subjects were then splitted into two equal groups of four (three males and one female) according to whether toothimplant FPDs were used or implant-implant supported partial FPDs. Patients of group I received a tooth-implant supported FPD constructed on the mandibular second premolar and connected to the dental implant at the site of the mandibular second molar. Patients of group II received an implant-implant FPD constructed on the mandibular second premolar and connected to a distal implant at the site of the second molar.

Titanium and threaded form of implants were utilized due to their favorable properties. Internal hex implants with antirotational design were used. A two-stage surgical approach was also utilized according to the original Branemark protocol, because it provides proper accessibility to implant fixture under soft tissue in the initial healing phase. One-stage protocol was not performed to avoid any incidence of implant fixture micromotion in the initial healing stage. In addition, flapless technique was not used due to the presence of anatomical variations in the lower posterior area. Drilling was done using a low speed, high torque motor and copious external irrigation to avoid bone overheating. Nonangled abutments were selected to direct the forces along the long axis of the implant. Three months were provided between implant insertion and loading to enable proper healing and osseointegration. A transfer-type impression coping technique was used due to its accuracy in case of a single implant lack of requirement for a custom tray. ${ }^{8}$ Cement retained super structures and rigid connectors were used for both groups of patients.

\section{Radiographic Evaluations}

Preoperative panoramic radiographs using the orthopantomograph OT 100 and CBCT images using Scanora 3D were made for each patient to evaluate the bone quality at the edentulous ridge of interest, buccolingual width, and the distance between the buccal and lingual plates of the alveolar canal. All abutment teeth were evaluated regarding their crestal bone height level, amount of supporting bone, continuity and regularity of lamina dura, presence of periapical pathosis, and root form and crown/root ratio. The presence or absence of any remaining roots or pathological conditions was assessed from the panoramic radiographs.

Cross-sectional cuts were taken at the proposed implant sites to evaluate the bone height level at the distal extension area between the crest of the ridge and superior most convex border of the inferior alveolar canal or the mental foramen. The preoperative measurements were completed on the cross-sectional images perpendicular to a line that was drawn equate to the inferior border of the mandible. Implant analog simulation was made for all patients at the proposed implant sites, whether the second molar area for group I patients or the second premolar and second molar areas for group II patients.

Immediately after loading (FPD cementation), the vertical bone length from the crest of the alveolar ridge (cervical reference line) to the implant tip (apical reference line) was recorded through $\mathrm{CBCT}$ radiograph. Records were taken from buccal, lingual, mesial, and distal aspects around the implant and the mean value of the records was presented. Three and 6 months later, $C B C T$ radiographs were made and the vertical bone length was recorded around the implants and the premolar abutments. The difference between the vertical bone lengths in successive radiographs represented vertical bone loss. A comparison between the vertical bone loss at the implant sites in tooth-implant and implant-implant supported was also done at a significance of $p<0.05$.

\section{Results}

With regard to bone density, no significant discrepancy appeared among the groups. These bone density differences were recorded immediately after loading, 3 months and 6 months later. Across all these time periods, it was seen that there was no significant difference in bone densities of both groups at the implant site. Table 1 has highlighted the results for both groups across the three aforementioned periods of time. These insignificant differences are further highlighted in Figure 1.

A comparison was made between the mean bone densities of both the groups regardless of the implant or abutment site. No significant differences among the mean bone densities of both the groups were noted. These differences were likewise recorded immediately after loading, 3 months and 6 months later. The insignificant differences are highlighted in Table 2 and Figure 2.

Comparisons were further made with regard to the variation by time observed in each group. With regard to tooth-implant supported FPD, it showed no statistically significant change in bone density after 3 months. However, it was noted that bone density was statistically significantly intensified after 6 months. With regard to the implant-implant supported FPD, bone density was statistically significantly intensified after 3 months as well as after 6 months. These results have been highlighted in Table 3 and Figure 3.

Meanwhile, a comparison was made between the percentage changes in bone density of two designs. No statistically significant 
Table 1: Comparison of bone densities with different designs at the implant site $(p<0.05)$

\begin{tabular}{lllllll}
\hline & \multicolumn{4}{c}{ Design } & \\
\cline { 2 - 3 } Time & \multicolumn{3}{c}{ Tooth-implant } & \multicolumn{2}{c}{ Implant-implant } & \\
\cline { 2 - 3 } & Mean & $S D$ & & Mean & $S D$ & p value \\
\hline Immediately & 752.3 & 84.3 & 769.2 & 41.4 & 0.688 \\
after loading & & & & & \\
3 months & 829.8 & 26.5 & 837.6 & 28.6 & 0.706 \\
6 months & 880.7 & 28.4 & 887.6 & 21.1 & 0.692 \\
\hline
\end{tabular}

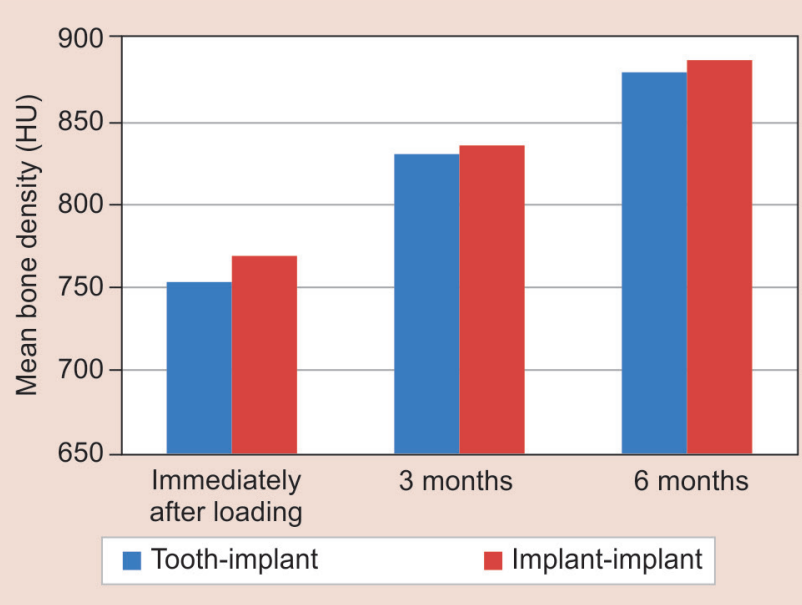

Fig. 1: Bone density with the two designs at the implant site

Table 3: Comparison of bone densities at variable time periods within each group $(p<0.05)$

\begin{tabular}{|c|c|c|c|c|}
\hline Group & Time & $\begin{array}{l}\text { Mean } \\
\text { difference }\end{array}$ & $S D$ & $p$ value \\
\hline \multirow[t]{2}{*}{ Tooth-implant } & $\begin{array}{l}\text { Immediately after } \\
\text { loading }-3 \text { months }\end{array}$ & 59.8 & 38.7 & 0.116 \\
\hline & $\begin{array}{l}\text { Immediately after } \\
\text { loading }-6 \text { months }\end{array}$ & 107.9 & 40.8 & 0.044 \\
\hline \multirow[t]{2}{*}{ Implant-implant } & $\begin{array}{l}\text { Immediately after } \\
\text { loading }-3 \text { months }\end{array}$ & 68.4 & 30.3 & 0.003 \\
\hline & $\begin{array}{l}\text { Immediately after } \\
\text { loading }-6 \text { months }\end{array}$ & 118.4 & 37.6 & 0.001 \\
\hline
\end{tabular}

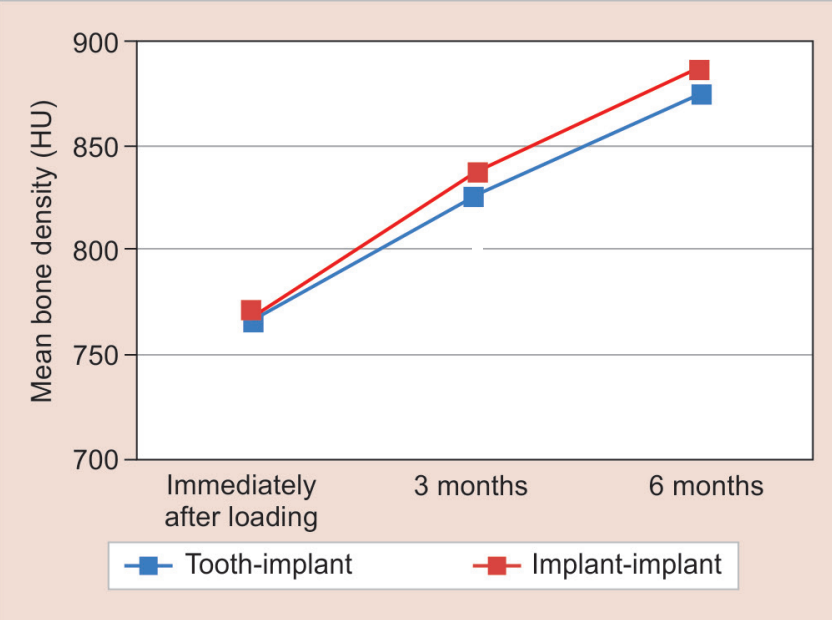

Fig. 3: Changes by time in mean bone density
Table 2: Comparison of bone density with the two designs $(p<0.05)$

\begin{tabular}{|c|c|c|c|c|c|}
\hline \multirow[b]{3}{*}{ Time } & \multicolumn{4}{|c|}{ Design } & \multirow[b]{3}{*}{$p$ value } \\
\hline & \multicolumn{2}{|c|}{ Tooth-implant } & \multicolumn{2}{|c|}{ Implant-implant } & \\
\hline & Mean & $S D$ & Mean & $S D$ & \\
\hline $\begin{array}{l}\text { Immediately } \\
\text { after loading }\end{array}$ & 766.6 & 68.1 & 769.2 & 41.4 & 0.944 \\
\hline 3 months & 826.4 & 29.5 & 837.6 & 28.6 & 0.599 \\
\hline 6 months & 874.5 & 27.4 & 887.6 & 21.1 & 0.449 \\
\hline
\end{tabular}

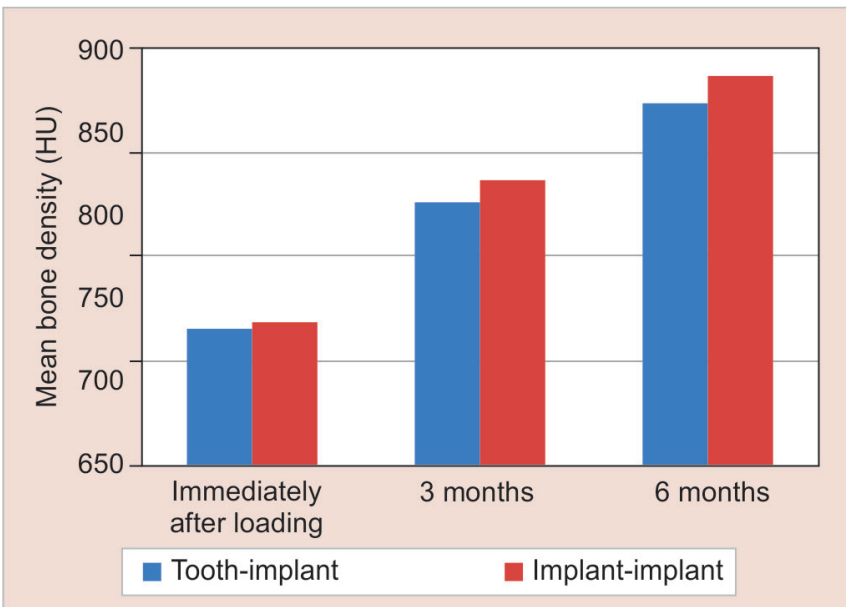

Fig. 2: Bone density with the two designs

Table 4: Comparison of percentage changes in bone density of the two designs $(p<0.05)$

\begin{tabular}{|c|c|c|c|c|c|}
\hline \multirow[b]{3}{*}{ Time } & \multicolumn{4}{|c|}{ Design } & \multirow[b]{3}{*}{$p$ value } \\
\hline & \multicolumn{2}{|c|}{ Tooth-implant } & \multicolumn{2}{|c|}{ Implant-implant } & \\
\hline & Mean & $S D$ & Mean & $S D$ & \\
\hline $\begin{array}{l}\text { Immediately } \\
\text { after loading- } \\
3 \text { months }\end{array}$ & 8.2 & 6.1 & 9 & 4.3 & 0.714 \\
\hline $\begin{array}{l}\text { Immediately } \\
\text { after loading- } \\
3 \text { months }\end{array}$ & 14.5 & 6.9 & 15.6 & 5.5 & 0.796 \\
\hline
\end{tabular}
Density (immediate)

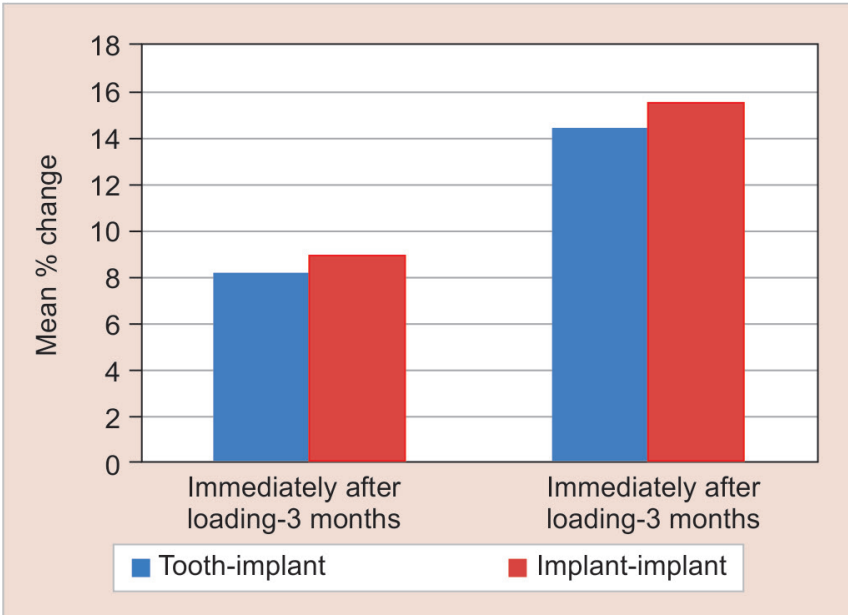

Fig. 4: Percentage changes in bone density of the two designs 
Table 5: Comparison of bone loss with the two designs at the implant site $(p<0.05)$

\begin{tabular}{|c|c|c|c|c|c|}
\hline \multirow[b]{3}{*}{ Time } & \multicolumn{4}{|c|}{ Design } & \multirow[b]{3}{*}{$p$ value } \\
\hline & \multicolumn{2}{|c|}{ Tooth-implant } & \multicolumn{2}{|c|}{ Implant-implant } & \\
\hline & Mean & $S D$ & Mean & $S D$ & \\
\hline 3 months & 0.14 & 0.08 & 0.11 & 0.02 & 0.714 \\
\hline 6 months & 0.21 & 0.09 & 0.18 & 0.03 & 0.714 \\
\hline
\end{tabular}

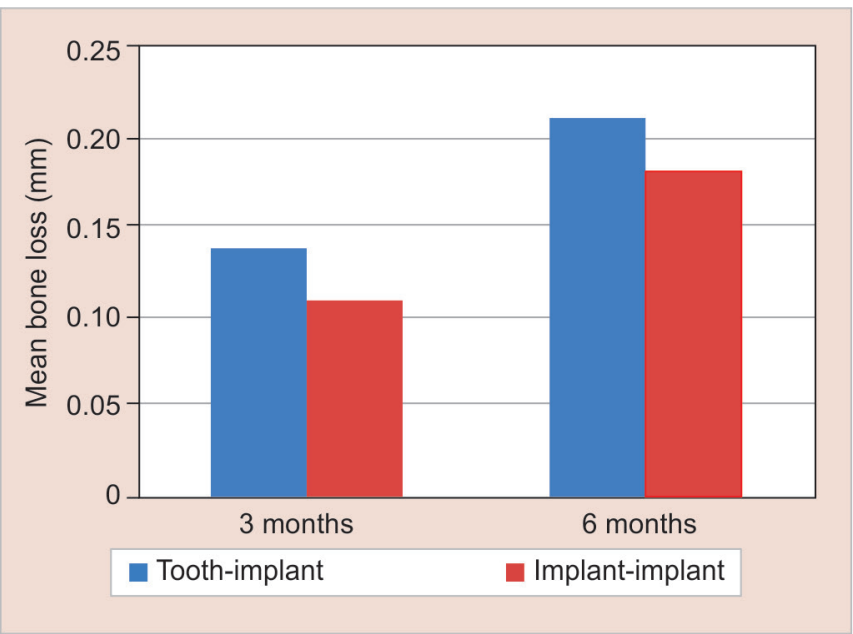

Fig. 5: Bone loss with the two designs at the implant site

discrepancy among the two groups was observed. The insignificant results have been highlighted in Table 4 and Figure 4.

Vertical bone loss was calculated as the difference between bone height immediately after loading and bone heights after 3 months and 6 months. A comparison was then made between among mean bone losses in the groups. These insignificant differences were noted after 3 months in addition to after 6 months. The results obtained for both the groups have been highlighted in Table 5 and Figure 5.

Furthermore, a comparison was made between the two designs regardless of implant or abutment site. No statistically significant discrepancy among bone losses in the groups was provided. These results were recorded after 3 months in addition to after 6 months. These results have been highlighted in Table 6 and Figure 6.

Also, a comparison was made with regard to the variation by time within each group. With regard to the tooth-implant supported FPD group, no significant loss of bone was seen in 6 months. This was additionally noted for the implant-implant supported FPD group. These results have been noted in Table 7 and Figure 7.

A further comparison was made between the percentage changes in vertical bone loss noted for both the groups. In this regard, it was seen that there was no statistically significant discrepancy among the designs, as noted in Table 8 and Figure 8.

\section{Discussion}

The transformation in the bone density loss is important because of limited study time. In studying enhancement of bone density, it is indicated that an entire new alveolar bone started packing the trabecular bone in 60-64 days. Considering the quantity of bone healing, Bosshardt et al. ${ }^{9}$ claimed that the mature new bone formation starts after 6-8 months of treatment, whereas crest woven formation initiates after 3 months. Several other
Table 6: Comparison of bone loss with the two designs $(p<0.05)$

\begin{tabular}{lllllll}
\hline \multicolumn{4}{c}{ Time } & \multicolumn{4}{c}{ Design } & \\
\cline { 2 - 3 } & Mean & $S D$ & & Mean & SD & p value \\
\hline 3 months & 0.17 & 0.11 & 0.11 & 0.02 & 0.905 \\
6 months & 0.25 & 0.14 & 0.18 & 0.03 & 0.548 \\
\hline
\end{tabular}

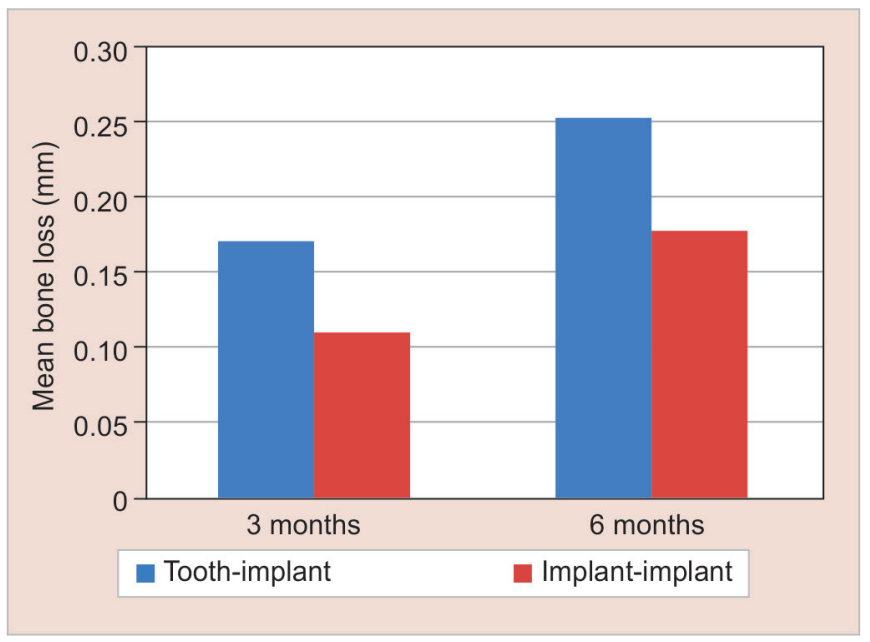

Fig. 6: Bone loss with the two designs

factors that contribute in the density transformations and alveolar loss are found insignificant in the current study. Therefore, the current study highlighted the effects of initial therapy, while excluding the surgical interventions for tissue regeneration. The healing mechanism of periodontal tissue repair is featured by the formation of connective or epithelial tissue after which new attachments are formed. ${ }^{10}$ This study had some limitations with respect to method of analysis and participants' age in order to achieve a substantial analysis of bone volume and density transformations. Few scholars, Bosshardt et al., ${ }^{9}$ and Michaud et al., ${ }^{11}$ have claimed that age risks were the causative factors of periodontitis. This is because of the reason that physiologically there is an alteration in periodontal tissue where bone healing and bone density possess a reaction to periodontal therapy to reduce. However, it is difficult to find the risk factors particularly in the elderly patients, while theoretically the alteration to the aging mechanism initiated at the age of 65 years. ${ }^{12}$

Considering the bone density in the current study, statistically insignificant difference is determined between mean bone densities in two different groups. This may be because of the low sample size of eight partially edentulous patients, aged between 30 years and 45 years. Three months pre- and posttreatment revealed no significant discrepancy in the average production of alveolar bone density. It has been observed a decrease in average bone in 3 months because the prior bone quality of patients was not identified. ${ }^{13}$ A study conducted by Otto et al. ${ }^{14}$ on 100 women of 45-year-old as an average age assembled into groups with normal and low bone mineral density showed that tooth mobilization was associated with bone density. The findings of the current study indicated that tooth mobilization is correlated with low bone density group.

In conclusion, the study demonstrated no significant discrepancy in loss and density of alveolar bone. Also, there is an 
Table 7: Comparison of bone loss at different time periods within each group $(p<0.05)$

\begin{tabular}{lllll}
\hline Group & Time & Mean & SD & p value \\
\hline Tooth-implant & $\begin{array}{l}\text { 3 months-6 } \\
\text { months }\end{array}$ & 0.08 & 0.02 & 0.109 \\
Implant-implant & $\begin{array}{l}3 \text { months-6 } \\
\text { months }\end{array}$ & 0.06 & 0.02 & 0.057 \\
\hline
\end{tabular}

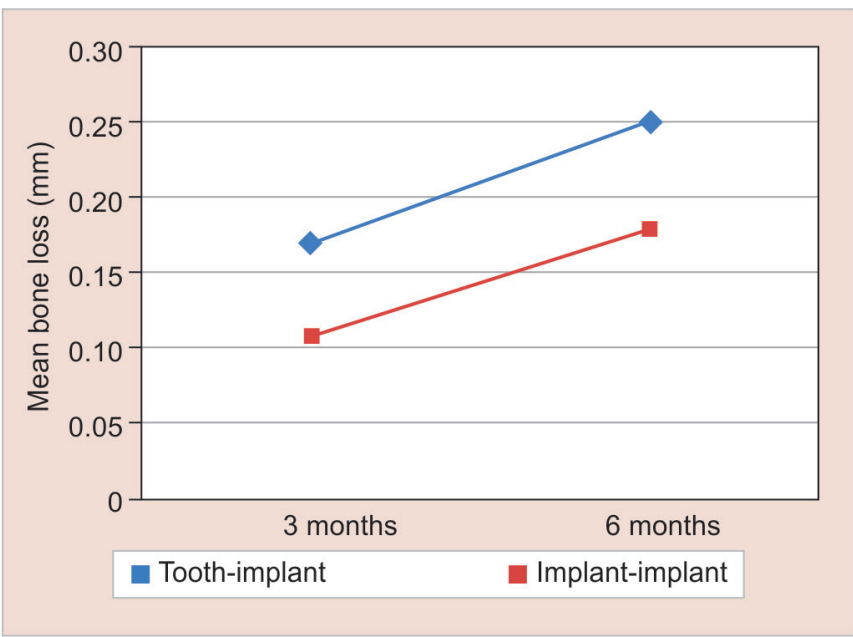

Fig. 7: Changes by time in mean bone loss

interrelation among tooth mobilizations and low bone density groups. For the implant-implant supported FPD group, the study provides that the mean bone loss significantly increases after 6 months. Enlargement of distal implant diameter tends to reduce the stress within the distal implant. Moreover, similar enlargement in the implant diameter decreased the stress in cancellous bone. Moderate enlargement in the length of distal implant is found to decrease the stress, while further enlargement in the length extends the stress within the distal implant. Finite element analysis indicated that the occlusal loads are predominantly spread to the crestal bone, as compared to the overall surface are of implant interface where they are distributed uniformly. As the masticatory forces are found to fragile and transient, these forces are generally supported by the bone. It is also recommended that further studies are required to analyze minimal alveolar bone healing for 4 months using a sample of young patients.

\section{References}

1. Albrektsson T, Dahl E, Enbom L, et al. Osseointegrated oral implants. J Periodontol 1988;59(5):287-296. DOI: 10.1902/jop.1988.59.5.287.

2. Lindh T, Dahlgren S, Gunnarsson K, et al. Tooth-implant supported fixed prostheses: a retrospective multicenter study. Int J Prosthodont 2001;14(4):321-328. DOI: 10.1034/j.1600-0501.2001.120503.x.

3. Brettle J. A survey of the literature on metallic surgical implants. Injury 1970;2(1):26-39. DOI: 10.1016/S0020-1383(70)80110-3.

4. Hoffmann O, Zafiropoulos GG. Tooth-implant connection: a review. J Oral Implantol 2012;38(2):194-200. DOI: 10.1563/AAID-JOI-D-10-00071.

5. Cohen SR, Orenstein JH. The use of attachments in combination implant and natural-tooth fixed partial dentures: a technical report. Int J Oral Maxillofac Implants 1994;9(2):230-234.
Table 8: Comparison between percentage changes in bone loss of the two designs $(p<0.05)$

\begin{tabular}{|c|c|c|c|c|c|}
\hline \multirow[b]{3}{*}{ Time } & \multicolumn{4}{|c|}{ Design } & \multirow[b]{3}{*}{$p$ value } \\
\hline & \multicolumn{2}{|c|}{ Tooth-implant } & \multicolumn{2}{|c|}{ Implant-implant } & \\
\hline & Mean & $S D$ & Mean & $S D$ & \\
\hline $3-6$ months & 62.4 & 22.4 & 55.9 & 9.9 & 0.548 \\
\hline
\end{tabular}

The percentage change was calculated as:

$\underline{\text { Density (immediate) - density (postoperative) }} \times 100$ Density (immediate)

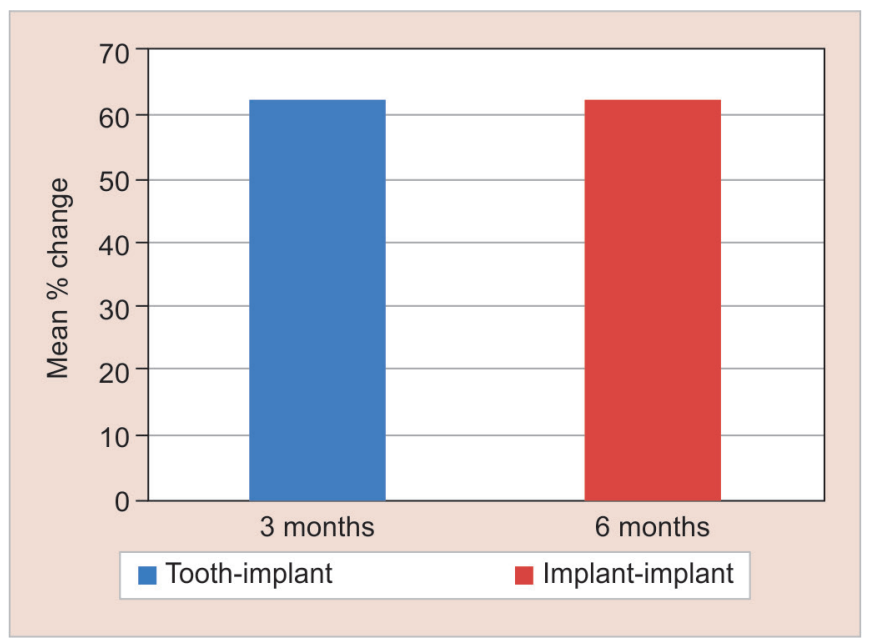

Fig. 8: Percentage changes in bone loss of the two designs

6. Pjetursson $B E$, Thoma $D$, Jung $R$, et al. A systematic review of the survival and complication rates of implant-supported fixed dental prostheses (FDPs) after a mean observation period of at least 5 years. Clin Oral Implants Res 2012;23(Suppl 6):22-38. DOI: 10.1111/j.16000501.2012.02546.x.

7. Chan HL, Misch K, Wang HL. Dental imaging in implant treatment planning. Implant Dent 2010;19(4):288-298. DOI: 10.1097/ ID.0b013e3181e59ebd.

8. Chee W, Jivraj S. Impression techniques for implant dentistry. Br Dent J 2006;201(7):429-432. DOI: 10.1038/sj.bdj.4814118.

9. Bosshardt DD, Chappuis V, Buser D. Osseointegration of titanium, titanium alloy and zirconia dental implants: current knowledge and open questions. Periodontol 2000 2017;73(1):22-40. DOI: 10.1111/ prd.12179.

10. Cheng F, Eriksson JE. Intermediate filaments and the regulation of cell motility during regeneration and wound healing. Cold Spring Harb Perspect Biol 2017;9(9):a022046. DOI: 10.1101/cshperspect.a022046.

11. Michaud DS, Fu Z, Shi J, et al. Periodontal disease, tooth loss, and cancer risk. Epidemiol Rev 2017;39(1):49-58. DOI: 10.1093/epirev/ $\mathrm{mxx} 006$.

12. Cabeza R, Albert M, Belleville $S$, et al. Maintenance, reserve and compensation: the cognitive neuroscience of healthy ageing. Nat Rev Neurosci 2018;19(12):772. DOI: 10.1038/s41583-018-0087-z.

13. Paschalis EP, Gamsjaeger S, Hassler N, et al. Vitamin D and calcium supplementation for three years in postmenopausal osteoporosis significantly alters bone mineral and organic matrix quality. Bone 2017;95:41-46. DOI: 10.1016/j.bone.2016.11.002.

14. Otto S, Pautke C, Jurado OM, et al. Further development of the MRONJ minipig large animal model. J Craniomaxillofac Surg 2017;45(9): 1503-1514. DOI: 10.1016/j.jcms.2017.07.002. 